\title{
Public Health Response to COVID-19 Cases in Correctional and Detention Facilities — Louisiana, March-April 2020
}

\begin{abstract}
Megan Wallace, DrPH ${ }^{1,2}$; Mariel Marlow, $\mathrm{PhD}^{2}$; Sean Simonson, $\mathrm{MPH}^{3}$; Marceia Walker, $\mathrm{MEd}^{3}$; Natalie Christophe, $\mathrm{MPH}^{3}$; Olivia Dominguez, $\mathrm{MPH}^{3}$; Lauren Kleamenakis, $\mathrm{MPH}^{3}$; Angie Orellana, $\mathrm{MPH}^{3}$; Doriselys Pagan-Pena, $\mathrm{MPH}^{3}$; Calandre Singh, $\mathrm{MPH}^{3}$; $\mathrm{Michele} \mathrm{Pogue}^{3}$; Leslie Saucier, $\mathrm{MPH}^{3}$; Terrence Lo, $\mathrm{DrPH}^{2}$; Kelsey Benson, $\mathrm{MPH}^{2}$; Theresa Sokol, $\mathrm{MPH}^{3}$
\end{abstract}

On May 8, 2020, this report was posted as an MMWR Early Release on the MMWR website (https://www.cdc.gov/mmwr).

Correctional and detention facilities face unique challenges in the control of infectious diseases, including coronavirus disease 2019 (COVID-19) (1-3). Among >10 million annual admissions to U.S. jails, approximately $55 \%$ of detainees are released back into their communities each week (4); in addition, staff members at correctional and detention facilities are members of their local communities. Thus, high rates of COVID-19 in correctional and detention facilities also have the potential to influence broader community transmission. In March 2020, the Louisiana Department of Health (LDH) began implementing surveillance for COVID-19 among correctional and detention facilities in Louisiana and identified cases and outbreaks in many facilities. In response, $\mathrm{LDH}$ and CDC developed and deployed the COVID-19 Management Assessment and Response (CMAR) tool to guide technical assistance focused on infection prevention and control policies and case management with correctional and detention facilities. This report describes COVID-19 prevalence in correctional and detention facilities detected through surveillance and findings of the CMAR assessment. During March 25-April 22, 489 laboratory-confirmed COVID-19 cases, including 37 (7.6\%) hospitalizations and $10(2.0 \%)$ deaths among incarcerated or detained persons, and 253 cases, including 19 (7.5\%) hospitalizations and four (1.6\%) deaths among staff members were reported. During April 8-22, CMAR telephone-based assessments were conducted with 13 of $31(42 \%)$ facilities with laboratory-confirmed cases and 11 of 113 (10\%) facilities without known cases. Administrators had awareness and overall understanding of CDC guidance for prevention of transmission in these facilities but reported challenges in implementation, related to limited space to quarantine close contacts of COVID-19 patients and inability of incarcerated and detained persons to engage in social distancing, particularly in dormitory-style housing. CMAR was a useful tool that helped state and federal public health officials assist multiple correctional and detention facilities to better manage COVID-19 patients and guide control activities to prevent or mitigate transmission.
On March 25, 2020, approximately 2 weeks after the first case of COVID-19 was reported in Louisiana, a case was reported in an incarcerated person. To assess COVID-19associated morbidity in this population, $\mathrm{LDH}$ epidemiologists contacted and enrolled correctional and detention facilities in an active surveillance system, in which a daily email requested a tally of laboratory-confirmed and suspected cases among detained and incarcerated persons and staff members, as well as the daily facility census for incarcerated and detained persons. The total number of facility staff members was not requested. On April 4, 2020, after preliminary analysis of surveillance data, LDH contacted CDC to request onsite technical assistance to describe the scope of the outbreaks, determine the degree of awareness and implementation of CDC COVID-19 guidance, and train regional epidemiologists to provide technical assistance to facilities. A CDC team arrived at $\mathrm{LDH}$ on April 6, 2020.

Because multiple outbreaks were identified across the state, $\mathrm{LDH}$ and CDC developed a telephone-based assessment tool to facilitate technical assistance to facilities with COVID-19 cases. CDC and LDH modeled the CMAR tool on an infection prevention and control assessment tool for health care facilities previously created by CDC.* CMAR guided telephone conversations with facility health administrators through important components of the CDC interim guidance on COVID-19 management in correctional and detention facilities (5). Recommended measures in the CDC guidance include 1) suspension of transfers of incarcerated and detained persons and visitation; 2) access to hand hygiene supplies, including running water, for both incarcerated or detained persons and staff members; 3) symptom screening and 14-day quarantine of incarcerated or detained persons upon intake to the facility before joining the general facility population; 4) symptom screening for staff members at the beginning of each shift; 5) dedication of space for medical isolation and quarantine; 6) symptom screening and coordination with local public health officials before release of incarcerated or detained persons; 7) personal protective equipment (PPE) use by staff members and incarcerated or detained persons who have duties

\footnotetext{
${ }^{*}$ https://www.cdc.gov/hai/prevent/infection-control-assessment-tools.html.
} 
that could involve exposure to an incarcerated or detained person with COVID-19; and 8) assignment of staff members to specific housing units. CMAR also provided prompts to facilitate discussion of challenges and lessons learned when implementing CDC guidance.

$\mathrm{LDH}$ epidemiologists invited health administrators and facility leadership from all facilities reporting cases among incarcerated or detained persons and a convenience sample of those that had not reported cases among incarcerated or detained persons to participate in technical assistance telephone calls using CMAR. To train LDH epidemiologists to perform technical assistance calls with facilities, a brief description of the recommended management strategy was provided after each question or section in CMAR. Responses to CMAR questions were transcribed during interviews. Facility characteristics, frequency of quantitative responses (e.g., ability to implement recommendations), and captured qualitative information are reported.

During March 25-April 22, 489 laboratory-confirmed COVID-19 cases among incarcerated or detained persons and an additional 253 cases among staff members were reported across 46 (32\%) of 144 correctional and detention facilities in Louisiana through active surveillance. There were 37 (7.6\%) hospitalizations and 10 (2.0\%) deaths related to COVID-19 among incarcerated or detained persons and 19 (7.5\%) hospitalizations and four (1.6\%) deaths among staff members. Among the 46 facilities with confirmed COVID-19 cases, 17 (37\%) reported cases in both incarcerated or detained persons and staff members, 15 (33\%) reported cases only in staff members, and 14 (30\%) reported cases only in incarcerated or detained persons. Facilities with cases were located in all nine Louisiana health regions and ranged in population size from 12 to $>5,000$ incarcerated or detained persons, housed juvenile and adult populations, and included 31 local jails, and 11 state, one federal, and three private facilities. Among the 31 facilities with cases in incarcerated or detained persons, the median period prevalence of confirmed COVID-19 cases among the facility population was $3 \%$ (range $=<0.01 \%-50 \%$; interquartile range $=1 \%-11 \%)$.

During April 8-22, 2020, CDC and LDH conducted 24 CMAR (Supplementary Material, https://stacks.cdc.gov/ view/cdc/87561) telephone-based assessments with health administrators and facility leadership (i.e., the sheriff or warden) including at 13 of 31 (42\%) facilities with laboratoryconfirmed cases in incarcerated or detained persons and 11 of $113(10 \%)$ facilities without known cases in incarcerated or detained persons. The populations housed in these facilities included men and women, adults and juveniles, and ranged in size from 14 to $>1,500$ incarcerated and detained persons. Dormitory-style housing was reported in $92 \%$ of facilities with cases and $64 \%$ of facilities without cases. Nine of 13 facilities reporting cases and six of 11 facilities without cases in incarcerated or detained persons also reported cases among staff members.

All 24 facilities reported implementing CDC recommendations for suspending visitation, providing appropriate hand hygiene supplies, and performing symptom screening of new intakes (Table). All but one facility reported performing symptom checks on staff members at shift change. Facility health administrators and leadership had awareness and overall understanding of the guidance but also reported challenges in implementation, primarily lack of space to individually quarantine close contacts of COVID-19 patients and the inability of incarcerated and detained persons to engage in social distancing, particularly in dormitory-style housing. Among 23 facilities that could implement medical isolation, most (eight of 12 facilities reporting cases and nine of 11 not reporting cases in incarcerated and detained persons) reported that they could medically isolate patients with suspected and confirmed COVID-19 individually, and the remaining facilities medically isolated confirmed COVID-19 patients in cohorts (i.e., in group housing situations instead of individual cells). Among 23 facilities that could implement quarantine, 10 of 12 facilities reporting cases, and six of 11 not reporting cases described limited capacity to individually quarantine asymptomatic close contacts of cases, and instead quarantined close contacts in cohorts.

Among 13 facilities reporting cases, 11 had suspended transfers to and from the facility; fewer (five of 11) facilities not reporting cases had suspended transfers. Among facilities continuing transfers, all reported decreasing their frequency. Symptom screening before release of incarcerated or detained persons was reported by six of 13 facilities reporting cases and two of 11 not reporting cases. The use of face masks or cloth face coverings for all incarcerated or detained persons was reported in nine of 13 facilities reporting cases, but in only three of 11 of those not reporting cases. Facilities often reported that staff members needed to work across multiple units, making it not feasible to assign staff members to a single housing unit; seven of 13 facilities reporting cases and three of 11 facilities not reporting cases had assigned staff members to specific units.

Facilities reported that disincentives to illness reporting by incarcerated or detained persons included an opposition to medical isolation, and that, in some instances, there was a cost attached to medical visits. Two facilities reported that daily symptom screening revealed persons with fever who were unaware of, or had not yet disclosed, their symptoms.

Some facilities implemented additional mitigation strategies, not currently described in CDC guidance, such as 
TABLE. Characteristics of facilities participating in the COVID-19 Management Assessment and Response (CMAR) $(N=24)$, by presence of COVID-19 cases among incarcerated or detained persons Louisiana, April 2020

\begin{tabular}{|c|c|c|}
\hline \multirow[b]{2}{*}{ Characteristic } & \multicolumn{2}{|c|}{ No. (\%) } \\
\hline & $\begin{array}{l}\text { Facilities that } \\
\text { reported COVID-19 } \\
\text { cases }(n=13)\end{array}$ & $\begin{array}{l}\text { Facilities that did not } \\
\text { report COVID-19 } \\
\text { cases }(n=11)\end{array}$ \\
\hline \multicolumn{3}{|l|}{ Population } \\
\hline Male & $13(100)$ & $10(91)$ \\
\hline Female & $6(46)$ & $8(73)$ \\
\hline Juvenile & $3(23)$ & $3(27)$ \\
\hline \multicolumn{3}{|l|}{ Facility description } \\
\hline \multicolumn{3}{|l|}{ Management } \\
\hline Local jail & $8(62)$ & $10(91)$ \\
\hline State & $3(23)$ & $0(-)$ \\
\hline Federal & $1(8)$ & $0(-)$ \\
\hline Private & $1(8)$ & $1(9)$ \\
\hline Reported cases in staff members & $9(69)$ & $6(55)$ \\
\hline Dormitory-style housing & $12(92)$ & $7(64)$ \\
\hline \multicolumn{3}{|l|}{ Interventions } \\
\hline Suspension of visitation & $13(100)$ & $11(100)$ \\
\hline Access to hand hygiene supplies & $13(100)$ & $11(100)$ \\
\hline $\begin{array}{l}\text { Symptom screening of } \\
\text { new intakes }\end{array}$ & $13(100)$ & $11(100)$ \\
\hline $\begin{array}{l}\text { Quarantine of new intakes } \\
\text { for } 14 \text { days }\end{array}$ & $9(69)$ & $7(64)$ \\
\hline In individual cells & $3(23)$ & $5(45)$ \\
\hline $\begin{array}{l}\text { Symptom screening for staff } \\
\text { members at entry }\end{array}$ & $13(100)$ & $10(91)$ \\
\hline \multicolumn{3}{|l|}{ Medical isolation of cases } \\
\hline In individual cells & $8(62)$ & $9(82)$ \\
\hline Cohorting & $4(31)$ & $2(18)$ \\
\hline No separate space available & $1(8)$ & $0(-)$ \\
\hline \multicolumn{3}{|l|}{ Quarantine of close contacts } \\
\hline In individual cells & $2(15)$ & $5(45)$ \\
\hline Cohorting & $10(77)$ & $6(54)$ \\
\hline No separate space available & $1(8)$ & $0(-)$ \\
\hline Suspension of transfers & $11(85)$ & $5(45)$ \\
\hline $\begin{array}{l}\text { Symptom screening before } \\
\text { release from facility }\end{array}$ & $6(46)$ & $2(18)$ \\
\hline $\begin{array}{l}\text { Universal masking of staff } \\
\text { members and inmates }\end{array}$ & $9(69)$ & $3(27)$ \\
\hline $\begin{array}{l}\text { Staff members assigned to } \\
\text { single units }\end{array}$ & $7(54)$ & $3(27)$ \\
\hline
\end{tabular}

Abbreviation: COVID-19 = coronavirus disease 2019.

decompression (i.e., early release and lowering bail to facilitate release), confirmation of a negative real-time reverse transcription-polymerase chain reaction (RT-PCR) test result before discontinuation of quarantine, and transport of COVID-19 patients to other facilities with more space for medical isolation. Facility staff members voiced concerns about asymptomatic transmission and potential for viral shedding after isolation, with implications for decisions regarding whom to test and when persons could be released from isolation or quarantine into general facility housing.

Two facilities reported that RT-PCR testing of asymptomatic close contacts of incarcerated and detained persons with COVID-19 for SARS-CoV-2, the virus that causes
COVID-19, at the end of their initial 14-day quarantine period resulted in positive test results for six of 10 contacts in one facility and nine of 19 in the other facility. Two facilities reported patients with COVID-19 who continued to have positive test results for SARS-CoV-2 at what would have been the end of their symptom-based medical isolation periods, and facility staff members voiced concern that patients released from isolation based on absence of symptoms might be infectious. To address this, these facilities described moving persons with positive SARS-CoV-2 test results into group "step-down" units, in which persons who had COVID-19 are cohorted together for an additional 7 days upon completion of their initial symptom-based medical isolation period. ${ }^{\dagger}$

\section{Discussion}

Interrupting SARS-CoV-2 transmission in confined, congregate settings creates unique prevention challenges (6-8). Louisiana has the second highest incarceration rate in the United States, with 144 correctional and detention facilities and an estimated daily correctional census of $45,400 . \$$ In Louisiana, staff members responding to interviews guided by the CMAR tool revealed awareness and overall understanding of CDC guidance. However, physical, logistical, and security constraints inherent to such settings make it difficult to fully implement the recommendations. The reported inability of some facilities to individually quarantine close contacts of incarcerated or detained persons with COVID-19 could result in spread among persons within the quarantine units.

CDC guidance currently recommends a 14-day quarantine for close contacts of a COVID-19 patient. If symptoms do not develop within those 14 days, movement restrictions can be lifted. However out of an abundance of caution, some facilities decided, in addition, to test quarantined persons before their release back into the general facility population. Some of these asymptomatic persons had positive SARS-CoV-2 test results at the end of quarantine, although it is not known if viable virus was present. Asymptomatic and presymptomatic persons have been shown to contribute to transmission in long-term care facilities (9). More research is needed to understand the role of asymptomatic and presymptomatic transmission in other

\footnotetext{
$\dagger$ Symptom-based release strategy refers to release from isolation occurring at least 3 days (72 hours) after recovery, defined as resolution of fever without the use of fever-reducing medications and improvement in respiratory symptoms (e.g., cough, shortness of breath), and at least 7 days since symptoms first appeared. On April 30, 2020, this period was extended to at least 10 days since symptoms first appeared. Test-based release strategy refers to release from isolation when there has been a resolution of fever without the use of feverreducing medications and improvement in respiratory symptoms and negative test results of a Food and Drug Administration Emergency Use Authorized molecular assay for COVID-19 from at least two consecutive upper respiratory tract swab specimens collected $\geq 24$ hours apart.

${ }^{\S}$ https://www.bjs.gov/content/pub/pdf/cpus16.pdf.
} 
congregate settings like correctional and detention facilities. If facilities choose to test asymptomatic persons in quarantine, or use the test-based approach (i.e., two negative test results at least 24 hours apart after resolution of symptoms) for release from isolation, additional medical isolation capacity might need to be secured. Facilities should be aware when using the test-based strategy for release from isolation that positive test results have been reported for longer than 14 days (up to 36 days) after symptom onset, although it is unknown if the persons with these test results are still infectious (10).

The findings in this report are subject to at least five limitations. First, the number of COVID-19 cases among staff members was not available for all facilities, so the total number of cases reported among staff members is likely an underestimate. Second, case finding is dependent on the facility's surveillance and testing practices, which might differ among facilities. Third, CMAR participation was voluntary and therefore might not be representative of all facilities in Louisiana. Fourth, the CMAR tool was being tested and revised throughout the investigation; thus, available information might differ slightly by facility. Finally, because CMAR is telephone based, the described interventions could not be directly evaluated by observation.

Correctional and detention facilities face unique challenges to the control of infectious diseases such as COVID-19 (1-3). Incarcerated and detained persons largely rely on the correctional or detention system for infection control and prevention within the facility. Correctional and detention facilities differ in size, population, facility layout, and operations, and no uniform approach will address the specific needs of all facilities. CMAR provides a systematic, accessible means to facilitate technical assistance by public health officials regarding CDC's interim guidance on management of COVID-19 in correctional and detention facilities and to build local capacity to serve the needs of such facilities within their jurisdictions (5). LDH staff members continue to conduct CMARs with facilities in the state. CMAR can be used by local, state, and federal public health agencies to assist correctional and detention facilities to better manage COVID-19 cases and guide control activities to prevent or mitigate SARS CoV-2 transmission. Preventing and mitigating transmission in these facilities not only protects the health of staff members and incarcerated and detained persons, it also protects the health of members of communities where these facilities are located.

\section{Acknowledgments}

Correctional and detention facility health services administrators and wardens; Liesl Hagan; Mary Ann Kirkconnell Hall; Katherine Hendricks; Dale Rose; Samantha P. Williams.

Corresponding author: Megan Wallace, phu3@cdc.gov, 404-718-3655.

\section{Summary}

What is already known about this topic?

COVID-19 can spread rapidly in correctional and detention facilities, where options for social distancing, isolation, and quarantine are limited.

What is added by this report?

In Louisiana, 46 facilities have reported 489 COVID-19 cases among incarcerated or detained persons and 253 cases among staff members. A COVID-19 Management Assessment and Response (CMAR) tool used to assess 24 facilities identified awareness and understanding of guidance. However, limited capacity to individually quarantine exposed persons and inability to engage in social distancing likely contributed to illness spread.

What are the implications for public health practice? Interrupting COVID-19 transmission in correctional and detention facilities is challenging. The CMAR tool could be used to assess COVID-19 management practices and guide strategies to address gaps.

\footnotetext{
${ }^{1}$ Epidemic Intelligence Service, CDC; ${ }^{2}$ CDC COVID-19 Emergency Response Team; ${ }^{3}$ Louisiana Department of Health.
}

All authors have completed and submitted the International Committee of Medical Journal Editors form for disclosure of potential conflicts of interest. No potential conflicts of interest were disclosed.

\section{References}

1. Bick JA. Infection control in jails and prisons. Clin Infect Dis 2007;45:1047-55. https://doi.org/10.1086/521910

2. Leung J, Elson D, Sanders K, et al. Notes from the field: mumps in detention facilities that house detained migrants-United States, September 2018-August 2019. MMWR Morb Mortal Wkly Rep 2019;68:749-50. https://doi.org/10.15585/mmwr.mm6834a4

3. Maruschak LM, Sabol WJ, Potter RH, Reid LC, Cramer EW. Pandemic influenza and jail facilities and populations. Am J Public Health 2009;99(Suppl 2):S339-44. https://doi.org/10.2105/ AJPH.2009.175174

4. Bureau of Justice Statistics. Jail inmates in 2016. Washington, DC: US Department of Justice, Bureau of Justice Statistics; 2018. https://www. bjs.gov/content/pub/pdf/ji16.pdf

5. CDC. Interim guidance on management of coronavirus disease 2019 (COVID-19) in correctional and detention facilities. Atlanta, GA: US Department of Health and Human Services, CDC; 2020. https://www. cdc.gov/coronavirus/2019-ncov/community/correction-detention/ guidance-correctional-detention.html

6. Moriarty LF, Plucinski MM, Marston BJ, et al.; CDC Cruise Ship Response Team; California Department of Public Health COVID-19 Team; Solano County COVID-19 Team. Public health responses to COVID-19 outbreaks on cruise ships-worldwide, February-March 2020. MMWR Morb Mortal Wkly Rep 2020;69:347-52. https://doi. org/10.15585/mmwr.mm6912e3

7. McMichael TM, Currie DW, Clark S, et al. Epidemiology of COVID-19 in a long-term care facility in King County, Washington. N Engl J Med 2020.Epub March 27, 2020.

8. Tobolowsky FA, Gonzales E, Self JL, et al. COVID-19 outbreak among three affiliated homeless service sites-King County, Washington, 2020. MMWR Morb Mortal Wkly Rep 2020;69:523-6. https://doi. org/10.15585/mmwr.mm6917e2 
9. Arons MM, Hatfield KM, Reddy SC, et al. Presymptomatic SARS$\mathrm{CoV}-2$ infections and transmission in a skilled nursing facility. N Eng J Med 2020. Epub April 24, 2020. https://doi.org/10.1056/ NEJMoa2008457
10. Kujawski SA, Wong KK, Collins JP, et al.; COVID-19 Investigation Team. Clinical and virologic characteristics of the first 12 patients with coronavirus disease 2019 (COVID-19) in the United States. Nat Med 2020. Epub April 23, 2020. https://www.ncbi.nlm.nih.gov/ pubmed/32327757?dopt=Abstract 